\title{
Reheparinisation requirements after cardiopulmonary bypass in patients treated with aprotinin
}

\author{
C R Bailey, A R Fisher, A K Wielogorski
}

\begin{abstract}
Objective-To determine reheparinisation requirements following protamine neutralisation after the discontinuation of cardiopulmonary bypass in a group of

explained by the presence of excessive protamine. Aprotinin may be a substrate for the $\mathbf{N}$-carboxypeptidase that destroys protamine, thus indirectly enhancing and prolonging the activity of protamine.
\end{abstract} patients receiving "low dose" aprotinin compared with a control group.

Design-Randomised, placebo controlled study.

Setting-Regional cardiothoracic unit within a district general hospital.

Patients-20 patients were consecutively allocated to one of two groups. All patients had a primary elective aortocoronary bypass operation using standard anaesthetic techniques and no patient was withdrawn from the study. Interventions-Aprotinin group patients $(n=9)$ received aprotinin $\left(1 \times 10^{6}\right.$ kallikrein inactivator units (KIU)) as an intravenous bolus after the induction of anaesthesia, and $1 \times 10^{6} \mathrm{KIU}$ was added to the pump prime. Control group patients $(n=11)$ received $0.9 \%$ saline placebo.

Main outcome measures-Activated clotting time (ACT), heparin concentration, and heparin dose response (HDR) measured before, during, and after bypass. The HDR is an accurate method to determine the patients' in vitro response to heparin and is used to predict the dose of heparin required to attain an ACT of 400 seconds.

Results-Activated clotting times were similar in the two groups for the duration of the study. Heparin concentrations were zero in all patients before heparin administration and after protamine neutralisation. During bypass there was no difference between the groups. The median heparin dose response was the same in the two groups before the administration of heparin, but after the neutralisation of heparin with protamine after the discontinuation of bypass the HDR was significantly higher in the aprotinin group for up to one hour (median of $2.9 \mathrm{IU} / \mathrm{ml} v 1.25$ in the control group at 10 minutes after protamine neutralisation, $P<0.01$; $2.5 v 1.45$ at $30 \mathrm{~min}-$ utes, $P<0.05$; and $2.9 v 1.6$ at one hour, $P<0.001$ ).

Conclusion-Heparin requirements were nearly doubled in patients treated with aprotinin, who required reheparinisation for up to one hour after protamine. This relative "heparin resistance" cannot be
(Br Heart f 1994;72:442-445)

Aprotinin (Trasylol, Bayer), a serine proteinase inhibitor derived from bovine lungs, significantly reduces postoperative blood loss and transfusion requirements in patients requiring cardiac surgery with cardiopulmonary bypass. ${ }^{12}$ After protamine neutralisation of heparin, if cardiopulmonary bypass needs to be reinstituted as an emergency, there have been several anecdotal reports of circuit coagulation despite apparently adequate reheparinisation. We used a total haemostasis management system (Hepcon/ HMS, Medtronic Hemotec, Englewood, Colorado, USA) to investigate reheparinisation requirements in a group of patients treated with aprotinin compared with a control group.

\section{Patients and methods}

Ethics committee approval and informed patient consent were obtained. A prospective, placebo controlled, randomised clinical trial was set up in patients scheduled to have an elective primary aortocoronary bypass operation with cardiopulmonary bypass. Patients having repeat operations or with a known previous exposure to aprotinin were excluded from the trial.

\section{APROTININ DOSE}

Aprotinin is supplied in clear vials, each containing $0.5 \times 10^{6}$ kallikrein inactivator units patients were consecutively allocated to one of two groups using a computer generated random number table.

The nine patients in the aprotinin group received an intravenous bolus of $100 \mathrm{ml}$ aprotinin $\left(1 \times 10^{6} \mathrm{KIU}\right)$ at induction of anaesthesia; $100 \mathrm{ml}$ aprotinin $\left(1 \times 10^{6} \mathrm{KIU}\right)$ was also added to the pump prime.

The 11 patients in the control group received an intravenous bolus of $100 \mathrm{ml} 0.9 \%$ saline solution at induction of anaesthesia; $100 \mathrm{ml} 0.9 \%$ saline solution was also added to the pump prime.

All patients were premedicated with intramuscular papaveretum (10-20 mg) and (KIU) in $50 \mathrm{ml} 0.9 \%$ saline solution. Twenty 
hyoscine $(0.2-0.4 \mathrm{mg})$ and lorazepam (1-2 $\mathrm{mg}$ ) by mouth. After intravenous induction of anaesthesia with diazepam and etomidate, intermittent positive pressure ventilation was supplemented with phenoperidine, pancuronium bromide, and isoflurane as necessary.

An intravenous bolus of either aprotinin or placebo was then administered. Porcine mucous heparin $(300 \mathrm{IU} / \mathrm{kg})$ was injected into a central vein before cannulation of the heart. Tests for activated clotting time (ACT) and heparin concentration (HC) were performed at regular intervals and further heparin given if the heparin concentration decreased to less than $2 \mathrm{IU} / \mathrm{ml}$.

A hollow fibre membrane oxygenator (Compactflo, Dideco) was primed with $500 \mathrm{ml}$ gelofusine, $1000 \mathrm{ml}$ compound sodium lactate, $100 \mathrm{ml} 8.4 \%$ sodium bicarbonate, $5000 \mathrm{IU}$ mucous sodium heparin, and $100 \mathrm{ml}$ aprotinin or $0.9 \%$ saline placebo. Flows of $2.41 / \mathrm{m}^{2} / \mathrm{min}$ were obtained with a minimally occlusive roller pump, and systemic hypothermia to $30^{\circ} \mathrm{C}$ was maintained while the aorta was occluded.

Myocardial preservation during aortic cross clamping was sustained with St Thomas's Hospital cardioplegic solution injected into the aortic root at $0^{\circ} \mathrm{C}$. The mean arterial pressure during bypass was kept between 50 and $80 \mathrm{~mm} \mathrm{Hg}$ with nitroglycerin, supplemented with phentolamine or metaraminol as necessary. After rewarming to $37^{\circ} \mathrm{C}$ at the completion of the operation and discontinuation of bypass, the residual effects of heparin were neutralised with protamine sulphate, the amount being determined from a measurement of heparin concentration immediately before separation from bypass.

After transfer to the intensive care unit, intermittent positive pressure ventilation was continued until the patient was warm peripherally, was not bleeding, and was otherwise stable. To maintain adequate filling pressures, blood was given if the measured packed cell volume was less than $30 \%$ and gelofusine if it was greater than $30 \% ; 1 \mathrm{ml} / \mathrm{kg} / \mathrm{h}$ intravenous crystalloid fluid was also given.

\section{MEASUREMENTS}

Anticoagulation was assessed in three ways. Firstly, the high range ACT (Hepcon/HMS) was measured. This is a qualitative test similar to the activated partial thromboplastin time. It is used to establish patient baseline clotting times and to determine if the initial heparin dose is adequate before cardiopulmonary bypass has begun. Although this test is com- monly used, it is of limited value as it is affected by haemodilution, hypothermia, platelet count, and platelet function.

Secondly, the HC (heparin/protamine titration, Hepcon/HMS) was measured. This is a quantitative test to determine the actual heparin concentration. It does not determine the heparin effect, however, and so is used in conjunction with the ACT, which can indicate a decreased response to heparin (such as decreased antithrombin III concentrations).

Thirdly, the HDR (Hepcon/HMS) was measured. This is an accurate method to determine the patients' in vitro response to heparin. It extrapolates to indicate the dose of heparin (IU/ml of circulating volume) needed to achieve an ACT of 400 seconds.

Measurements were performed at three times: (a) before cardiopulmonary bypass (baseline ACT, HC, and HDR before aprotinin and heparin; ACT, HC, and HDR after aprotinin but before heparin; and ACT, HC, and HDR after heparin); (b) during cardiopulmonary bypass (ACT and HC at 10, 30 , and 60 minutes of bypass; just before the discontinuation of bypass a heparin assay was performed for each patient to predict the protamine dose required for heparin neutralisation and this protamine dose was then given after the patient was separated from the bypass circuit); and, (c) after cardiopulmonary bypass (ACT, HC, and HDR 10, 30, and 60 minutes after the administration of protamine).

Haemoglobin concentration, platelet counts, and clotting were measured by routine laboratory methods. Mediastinal blood shed during bypass was reinfused, together with all the remaining volume in the cardiopulmonary bypass reservoir at the end of bypass. After the insertion of chest drains, losses were measured hourly until their removal 18-24 hours later (recorded as "postoperative losses"). No cell saver device was used during the study.

\section{STATISTICAL ANALYSIS}

Normally distributed data were analysed by unpaired Student's $t$ tests. Data not normally distributed were assessed by Mann-Whitney $U$ tests. Significant differences were assumed at $\mathrm{P}<0.05$.

\section{Results}

Table 1 gives the demographic data of the patients studied. The groups were well matched in terms of age and body surface

Table 1 Demographic data of study groups

\begin{tabular}{|c|c|c|}
\hline & $\begin{array}{l}\text { Control group } \\
(n=11)\end{array}$ & $\begin{array}{l}\text { Aprotinin group } \\
(n=9)\end{array}$ \\
\hline $\begin{array}{l}\text { Mean (SD) age (years) } \\
\text { Mean (SD) body surface area }\left(\mathrm{m}^{2}\right) \\
\text { Male/female ratio } \\
\text { Median (range) cardiopulmonary bypass time (minutes) } \\
\text { Median (range) coronary ischaemia time (minutes) } \\
\text { Median (range) postoperative blood loss (ml) } \\
\text { Median (range) } 18 \text { hour postoperative urine volume (l) } \\
\text { Median (range) protamine (mg)/heparin ( } \times 100 \mathrm{IU} \text { ) ratio }\end{array}$ & $\begin{array}{l}61(12 \cdot 6) \\
1 \cdot 91(0 \cdot 22) \\
10 / 1 \\
74(46-98) \\
29(16-45) \\
480(210-2260) \\
2 \cdot 19(1 \cdot 77-4 \cdot 88) \\
0 \cdot 66(0 \cdot 48-0 \cdot 87)\end{array}$ & $\begin{array}{l}59(7 \cdot 4) \\
1.82(0 \cdot 34) \\
8 / 1 \\
57(27-92) \\
34(17-46) \\
345(90-1180) \\
2 \cdot 31(1 \cdot 60-3 \cdot 00) \\
0.67(0.51-0.89)\end{array}$ \\
\hline
\end{tabular}


Table 2 Activated clotting time(s) throughout study period; median (range)

\begin{tabular}{lll}
\hline & $\begin{array}{l}\text { Control group } \\
(n=11)\end{array}$ & $\begin{array}{l}\text { Aprotinin group } \\
(n=9)\end{array}$ \\
\hline $\begin{array}{l}\text { Before aprotinin, before heparin } \\
\text { After aprotinin, before heparin }\end{array}$ & $124(108-184)$ & $\begin{array}{l}121(110-127) \\
115(93-137)\end{array}$ \\
$\begin{array}{l}\text { After heparin } \\
\text { During CPB: }\end{array}$ & $465(392-807)$ & $534(419-677)$ \\
$\quad 10 \mathrm{~min}$ & $573(412-981)$ & $922(470-1300)$ \\
$30 \mathrm{~min}$ & $598(392-1106)$ & $585(444-1023)$ \\
$60 \mathrm{~min}$ & $458(339-758)$ & $587(452-683)$ \\
$(\mathrm{n}=6)$ & $109(103-140)$ \\
After protamine: & $117(99-145)$ & $107(102-118)$ \\
$30 \mathrm{~min}$ & $115(86-134)$ & $100(95-126)$ \\
$60 \mathrm{~min}$ & $122(100-162)$ & \\
\hline
\end{tabular}

$\mathrm{CPB}=$ Cardiopulmonary bypass.

Table 3 Haemostasis tests throghout study period; median (range)

\begin{tabular}{|c|c|c|}
\hline & $\begin{array}{l}\text { Control group } \\
(n=11)\end{array}$ & $\begin{array}{l}\text { Aprotinin group } \\
(n=9)\end{array}$ \\
\hline $\begin{array}{l}\text { HDR before aprotinin } \\
\text { HDR after aprotinin }\end{array}$ & $2.9(1.8-4 \cdot 0)$ & $3 \cdot 4(2 \cdot 5-5 \cdot 7)$ \\
\hline HC after heparin & $2.75(2 \cdot 0-3 \cdot 5)$ & $3 \cdot 0(2 \cdot 5-3 \cdot 5)$ \\
\hline $\mathrm{HC} 10 \mathrm{~min} C P B$ & $2 \cdot 0(1 \cdot 5-3 \cdot 0)$ & $2 \cdot 0(1 \cdot 5-2 \cdot 5)$ \\
\hline $\mathrm{HC} 30 \mathrm{~min} \mathrm{CPB}$ & $1.75(1.5-3.5)$ & $2 \cdot 5(1.5-2 \cdot 5)$ \\
\hline $\mathrm{HC} 60 \mathrm{~min} \mathrm{CPB}$ & $2 \cdot 0(1 \cdot 5-2 \cdot 5)$ & $2 \cdot 5(2 \cdot 0-2 \cdot 5)$ \\
\hline HDR after protamine & $1 \cdot 25(1 \cdot 0-2 \cdot 7)$ & $2 \cdot 9(1 \cdot 3-4 \cdot 0)^{\star}$ \\
\hline HDR $30 \mathrm{~min}$ after protamine & $1 \cdot 45(1 \cdot 2-2 \cdot 7)$ & $2 \cdot 5(1 \cdot 1-3 \cdot 2) \dagger$ \\
\hline HDR 60 min after protamine & $1.6(1.4-1.9)$ & $2 \cdot 9(1.9-3 \cdot 3) \ddagger$ \\
\hline
\end{tabular}

$\star P<0.01,+P<0.05, \ddagger P<0.001$, Mann-Whitney $U$ test.

$\mathrm{CPB}=$ Cardiopulmonary bypass; $\mathrm{HC}=$ heparin concentration $(\mathrm{IU} / \mathrm{ml}) ; \mathrm{HDR}=$ heparin dose response (IU/ml). investigated, its mode of action has not yet been fully elucidated. It may act in one or more of the following ways: preservation of platelet glycoprotein $1 \mathrm{~b}$ to maintain platelet adhesiveness ${ }^{3}$; attenuation of the intrinsic clotting pathway; ${ }^{4-6}$ or antifibrinolysis. ${ }^{78}$

Although no definitive study has shown an increased incidence of graft occlusion in aprotinin treated patients, Bohrer et $a l^{l}$ reported aprotinin associated thrombus formation and Samama et $a l^{10}$ showed an increase in spontaneous femoral artery thrombosis in pigs treated with aprotinin compared with a control group. Because any potential prothrombotic tendency may be dose dependent, we studied "low dose" aprotinin, which we have previously shown to be efficacious in aspirin treated patients requiring primary cardiac surgery. ${ }^{11}$ In the present study postoperative blood loss was reduced in the aprotinin group but did not achieve statistical significance because, in the context of wide variations in blood loss, the study was too small.

The baseline predicted dose of heparin required to attain an ACT of 400 seconds (HDR) was similar in the aprotinin group (before and after the patient bolus of $10^{6} \mathrm{KIU}$ aprotinin) and the control group. De Smet et al showed that aprotinin prolongs the ACT, probably due to kallikrein inhibition limiting the activation of factor XII and thus the early phase of the intrinsic pathway, so that fewer coagulation factors through the coagulation cascade become activated. ${ }^{5}$ Hunt et al ${ }^{12}$ showed that this increase in the presence of aprotinin is dose dependent, and we found a slight increase in the ACT in the group receiving aprotinin compared with controls. In the presence of "high dose" aprotinin (that is, antikallikrein dose), Hunt et al recommend maintaining the ACT at 750 seconds during cardiopulmonary bypass. Because we were monitoring the HC, however, heparin was administered according to this parameter rather than the ACT. During the bypass period, anticoagulation was adequate and similar in the two groups as judged by the HC and ACT. At the end of the bypass period the HC was measured for each patient and an individual protamine requirement was calculated and administered. The ratio of protamine to total heparin given to the two groups of patients (means of 0.66 and 0.67 in the control group and aprotinin group respectively) were less than the $1: 1$ ratio given in most centres.

Although the ACT returned to baseline in the two groups of patients, from the results of the present study it appears that heparin requirements are nearly doubled in aprotinin treated patients who require reheparinisation for up to one hour after protamine compared with controls; this phenomenon of relative "heparin resistance" cannot be explained by the presence of excessive protamine administration as suggested by Hunt and Murkin. ${ }^{13}$ As an alternative explanation, we postulate that aprotinin may be a substrate for the $\mathrm{N}$ carboxypeptidase that destroys protamine sulphate. If this is so, then the activity of protamine, $2.5 v 1.45$ at 30 minutes, and $2.9 v$ 1.6 at one hour after protamine).

\section{Discussion}

There is now irrefutable evidence that aprotinin reduces blood loss after cardiac surgery. ${ }^{12}$ Cardiopulmonary bypass has extensive effects on the mechanism of coagulation, which predispose patients to excessive bleeding after the operation, and although the physiochemical effects of aprotinin have been extensively 
protamine would become enhanced and prolonged in the continuing presence of aprotinin. More work is clearly required to elucidate this phenomenon of heparin resistance after protamine; in the meantime we recommend the administration of double the normal dose of heparin in patients pretreated with aprotinin who require emergency reheparinisation and reinstitution of cardiopulmonary bypass.

We thank Mr J B O'Riordan and Mr F P Shabbo, consultant cardiac surgeons, for allowing us to study their patients; we also thank the nursing staff in the operating theatres and intensive care unit for their cooperation, and the cardiothoracic unit, Brook Hospital for financial assistance towards this research project.

1 Bidstrup BP, Royston D, Sapsford RN, Taylor KM. Reduction in blood loss and blood use after cardiopulmonary bypass with high-dose Aprotinin (Trasylol). monary bypas Cardiovasc Surg 1989;97:364-72.

2 Royston D, Bidstrup BP, Taylor KM, Sapsford RN. Effect of aprotinin on need for blood transfusion after repeat of aprotinin on need for blood transfusion
open heart surgery. Lancet 1987;ii:1289-91.

3 Van Oeveren W, Harder MP, Roozendaal KJ, Eijsman L, Wildevuur CRH. Aprotinin protects platelets against the initial effect of cardiopulmonary bypass. $\mathcal{F}$ Thorac Cardiovasc Surg 1990;99:788-97.
4 Dietrich W, Spannagl M, Jochum M, et al. Influence of high-dose aprotinin treatment on blood loss and coagulation patterns in patients undergoing myocardial revascution patterns in patients undergoing myocardig
larisation. Anesthesiology 1990;73:1119-26.

5 De Smet AAEA, Joen MCN, Van Oeveren W, et al. Increased anticoagulation during cardiopulmonary bypass by aprotinin. $\mathcal{F}$ Thorac Cardiovasc Surg 1990;100: 520-7.

$6 \mathrm{Lu} \mathrm{H}$, Soria C, Commin PL, et al. Haemostasis in patients undergoing extracorporeal circulation:the effect of aprotinin (Trasylol). Thromb Haemost 1991;66:633-7.

7 Havel M, Teufelsbauer H, Knobl P, et al. Effect of intraoperative aprotinin administration on postoperative bleeding in patients undergoing cardiopulmonary bypass operations. ₹ Thorac Cardiovasc Surg 1991;101:968-72.

8 Blauhut B, Gross C, Necek S, Doran JE, Spath P, Lundsgaard-Hansen P. Effect of high dose aprotinin on blood loss, platelet function, fibrinolysis, complement, and renal function after cardiopulmonary bypass. and renal function after cardiopulmonary

9 Bohrer H, Fleisher F, Lang J, Vahl C. Early formation of thrombi on pulmonary artery catheters in cardiac surgical patients receiving high-dose aprotinin. $f$ Cardiothorac Vasc Anesth 1990;4:222-5.

10 Samama ChM, Mazoya E, Bruneval P, et al. Aprotinin does not decrease surgical bleeding and could promote arterial thrombosis in the pig: a prospective randomized, blind, study. Br ₹ Anaesth 1993;70(Suppl 1):A100.

11 Bailey CR, Wielogorski AK. Randomised placebo controlled double blind study of two low dose aprotinin regimens in cardiac surgery. Br Heart $₹$ 1994;71:349-53.

12 Hunt BJ, Segal HC, Yacoub M. Guidelines for monitoring heparin by the activated clotting time when aprotinin is used during cardiopulmonary bypass. $\mathcal{f}$ Thorac is used during cardiopulmona

13 Hunt BJ, Murkin JM. Heparin resistance after aprotinin. Lancet 1993;341:126. 